\title{
Limitações ao uso de espécies florestais nativas pode contribuir com a erosão do conhecimento ecológico tradicional e local de agricultores familiares ${ }^{1}$
}

\author{
Elaine Zuchiwschi ${ }^{2,4}$, Alfredo Celso Fantini², Antonio Carlos Alves ${ }^{3}$ e Nivaldo Peroni ${ }^{2}$
}

Recebido em 2/09/2009. Aceito em 4/01/2010

\begin{abstract}
RESUMO - (Limitações ao uso de espécies florestais nativas pode contribuir com a erosão do conhecimento ecológico tradicional e local de agricultores familiares). O conhecimento ecológico tradicional ou local é construído a partir da relação contínua de humanos com o meio ambiente, principalmente pelo uso cotidiano das espécies. O abandono do uso, por sua vez, pode provocar perda desse tipo de conhecimento, o que freqüentemente decorre de mudanças no modo de vida. Neste trabalho buscou-se avaliar o conhecimento e o uso efetivo, atual e passado, de espécies vegetais das Florestas Estacional Decidual e Ombrófila Mista por agricultores familiares da região Oeste de Santa Catarina. Os métodos de coleta e análise de dados basearam-se numa integração de métodos qualitativos e quantitativos em Etnobotânica. Os resultados revelaram que esses agricultores possuem um amplo conhecimento a respeito das espécies florestais nativas da região e seu uso efetivo atual se destina ao autoconsumo nas unidades de produção, destacando-se a dependência do uso como lenha. No entanto, os usos madeireiros têm sido reduzidos nos últimos anos devido, principalmente, a limitações ao acesso legal às espécies florestais nativas. Agricultores com mais de 40 anos citaram uma riqueza maior de espécies, com uma distribuição mais equitativa dela, do que aqueles com menos de 40 anos. Houve também atenuação na correlação entre conhecimento e uso atual de espécies entre os mais jovens. Os dados sugerem que existe um processo gradual de perda das condições de transmissão do conhecimento tradicional local com risco de erosão do conhecimento acumulado. Palavras-chave: etnobotânica quantitativa, agricultura familiar, Floresta Estacional Decidual, legislação florestal, Mata Atlântica
\end{abstract}

ABSTRACT - (Limitations of native forest species use may contribute to erosion of traditional and local ecological knowledge among family farmers). Traditional or local ecological knowledge is developed from the continuous relationship between humans and their environment, mainly through the daily use of natural resources. The abandonment of uses, on the other hand, may cause the loss of this kind of knowledge, which frequently occurs due to changes in life style. In this paper, we aimed to evaluate the knowledge and the dynamics of the effective use of native forests in western Santa Catarina state, Brazil. Data collection and analysis were based on the integration of qualitative and quantitative ethnobotanical methods. The results revealed that farmers have comprehensive knowledge of the native forest species of the region and the effective present use of these forest resources is mainly for subsistence, highlighting the dependence of farmers on firewood. However, timber use has declined in recent years due, mainly, to limitations of legal access to native forest species. Farmers older than 40 years cited higher species richness, with a more equitable distribution of species, compared to younger farmers. In addition, attenuation of the correlation between knowledge and present use of species among younger people was noticed. The data suggest the existence of a gradual process of loss of transmission of traditional local knowledge and that there is a risk of erosion of accumulated knowledge.

Key words: quantitative ethnobotany, family farming, Seasonal Deciduous Forest, forest regulations, Brazilian Mata Atlântica

\section{Introdução}

Agricultores tradicionais possuem um extenso conhecimento de plantas e do manejo do ambiente em que vivem (Peroni et al. 2008). A construção do conhecimento sobre os recursos naturais é conseqüência da produção baseada na subsistência, sua transmissão ocorre via experiência pessoal direta, de forma oral, e o uso é validado por sua relevância cotidiana no sistema de subsistência da família (Hunn 1999).

O conhecimento acumulado no contato de humanos com recursos naturais freqüentemente é denominado de "conhecimento ecológico tradicional", termo que faz referência, principalmente, à questão temporal da adaptação e transmissão desse conhecimento entre gerações (Gadgil et al. 1993). O termo "conhecimento local" também é utilizado para esse tipo de conhecimento, enfatizando, neste caso, o aspecto espacial e seu caráter híbrido, por ser produzido a partir da combinação de elementos naturais, sociais e técnicos muito diversos (Guivant 1997), como propõe a teoria de "actor-network" (Callon 1986; Latour 1987) que aponta para uma interdependência entre o conhecimento científico e o local, e para a hibridização ou fusão de horizontes.
O contexto social e político do final do século XX transformou o significado do uso do conhecimento tradicional, assim como as formas de organização e de controle local pelas comunidades locais (Alexiades 2003). Segundo este autor, estes conhecimentos ganharam um destaque impar, uma vez que há interesses tecnológicos, sociais, econômicos, políticos e ambientais envolvidos. Este cenário condiz com a necessidade de desenvolvimento local, em grande parte, no contexto de populações rurais, muitas vezes organizadas como comunidades de agricultores familiares. Muitas comunidades mostram alguma forma de controle local sobre os recursos naturais, o que pode formar a base para propostas de políticas públicas para manejo local ou manejo comum dos recursos (Berkes et al. 2000). O conhecimento ecológico tradicional e local pode fornecer informações de grande relevância atual sobre funções ecológicas e sobre o manejo e a conservação de recursos naturais em processos que envolvam as populações locais (Cunningham 1996; Hanazaki 2003).

No entanto, a erosão do conhecimento tradicional é uma preocupação recente já que está muito associada ao abandono do uso dos recursos e mudanças no modo de vida das

\footnotetext{
Parte da Dissertação de Mestrado da primeira Autora

2 Universidade Federal de Santa Catarina, Programa de Pós-graduação em Recursos Genéticos Vegetais, Florianópolis, SC, Brasil

3 Universidade Federal de Santa Catarina, Centro de Ciências Agrárias, Depto. de Fitotecnia, Florianópolis, SC, Brasil

4 Autor para correspondência: ezuchws@yahoo.com.br
} 
populações (Hunn 1999; Reyes-Garcia et al. 2005). Entre indígenas Tawahka, de Honduras a erosão do conhecimento a respeito de plantas e animais pode estar associada à participação no mercado de plantas cultivadas e ao trabalho assalariado, gerando redução no extrativismo (Godoy et al. 1998). Entre comunidades mexicanas localizadas na Reserva da Biosfera da Serra de Manantlan, verificou-se que a erosão do conhecimento estava associada à perda da linguagem indígena e à aquisição de serviços comunitários não tradicionais (Benz et al. 2000). Em ilhas do Pacífico, a introdução da educação formal com currículo baseado na cultura ocidental tem tido um impacto expressivo no conhecimento local (Ruddle 2000).

Os camponeses e agricultores familiares brasileiros tiveram que se adaptar aos distintos ecossistemas que ocuparam e garantir seu sustento basicamente a partir dos recursos naturais disponíveis, sobre os quais acumularam conhecimento. O modelo patronal de agricultura foi privilegiado no país, e a agricultura familiar nasceu sob precariedade jurídica, econômica e social do controle dos meios de trabalho, de produção e da terra (Brumer et al. 1993). Na região Sul do Brasil, os agricultores familiares dependeram das florestas nativas em suas trajetórias de vida e comercializaram diversos produtos como a erva-mate (Ilex paraguarienses), pinhão (Araucaria angustifolia), palmito (Euterpe edulis) e madeira (diversas espécies), atividades que ainda persistem (Reis 2006; Fantini \& Siminski, 2007; Baldauf et al 2007). Nas unidades de produção familiar, persiste também o autoconsumo de espécies florestais nativas para obtenção de energia (lenha), para construção de residências e outras benfeitorias, uso alimentar de frutas nativas e, uso medicinal de diversas espécies (Reis 2006).

No entanto, nas últimas décadas, o uso e o manejo de espécies florestais nativas por populações tradicionais e rurais na área de abrangência do bioma Mata Atlântica, tem sofrido restrições, gerando conflitos de uso, principalmente devido à aplicação da legislação ambiental e à criação de unidades de conservação (Siminski \& Fantini 2007; Neumann \& Loch 2002; Zanoni et al. 2000). Analisando a questão no estado de Santa Catarina, sob um ponto de vista sistêmico, Siminski (2009) sugere que a restrição ao uso e manejo dos recursos como estratégia de promover a preservação florestal tem resultado em um ciclo de retroalimentação oposto ao desejado, ou seja, a existência de ecossistemas florestais nativos passou a ser encarada como inconveniente e não como oportunidade pelos agricultores e produtores rurais para a conservação e o uso de espécies nativas.

Este trabalho teve como objetivo analisar o uso e o conhecimento de agricultores familiares do município de Anchieta - Santa Catarina, sobre espécies vegetais de florestas nativas. Foi feita uma breve descrição do conhecimento sobre espécies e usos e analisado o efetivo uso das espécies, no passado e atualmente, agregado a informações de categorias de uso e do contexto sócio-ambiental e econômico. Foi também analisada a relação entre conhecimento e uso das espécies pelos agricultores, agrupados em faixas etárias. Essas informações são úteis para avaliar o processo de erosão e transformação do conhecimento tradicional ou local, dentro de um contexto específico.

É importante ressaltar que o trabalho realizado partiu de uma demanda de atores sociais do município, interessados em valorizar o conhecimento local associado à biodiversidade.

\section{Material e métodos}

Área do estudo - $\mathrm{O}$ estudo foi conduzido no município de Anchieta (26³1'48'S; 5319'48'O), localizado no extremo Oeste do estado de Santa Catarina, região Sul do Brasil (Fig. 1). De acordo com o censo oficial, a população atual é de 6.587 habitantes (contagem de 2007) (IBGE 2009a), cuja maior parte (65,8\%) vive no meio rural (Epagri/CEPA 2007) praticando uma agricultura baseada na mão-de-obra familiar. As unidades de produção agropecuárias são pequenas ( $93 \%$ tem até 50 ha), a grande maioria de propriedade privada, com reduzido uso de insumos industrializados. Os principais produtos agropecuários do município são milho, fumo, feijão, soja e leite (Epagri/CEPA 2007).

O município conta com 913 unidades de produção agropecuárias em atividade, distribuídos em 31 comunidades rurais. Estas comunidades rurais estão estruturadas como associações, possuem nome e foram criadas já nos primeiros anos em que os agricultores descendentes de europeus se estabeleceram no município. As comunidades possuem em suas sedes uma construção onde são realizados cultos ecumênicos e onde funcionava a escola no passado, além de bodega (pequeno bar e mercearia), podendo ter também campo de futebol e cancha para bocha.

O clima do município de Anchieta, seguindo a classificação Koeppen, é do tipo Cfa-Mesotérmico, com estações definidas e geadas no inverno, a temperatura média anual é de $18^{\circ} \mathrm{C}$ e a pluviosidade anual média é de 1.900 a $2.000 \mathrm{~mm}$ (IBGE, 1990). Predomina o relevo montanhoso na maior parte do município, em altitudes que variam entre 500 a 950 metros. A vegetação natural caracteriza-se como Floresta Estacional Decidual e Floresta Ombrófila Mista, ocupando aproximadamente $85 \%$ e 15\% da área do município, respectivamente.

A região Oeste do estado de Santa Catarina teve seu povoamento intensificado a partir da década de 1920, mas principalmente entre 1930 e 1940, pela migração de agricultores vindos do estado do Rio Grande do Sul, descendentes de europeus (segunda ou terceira geração), principalmente de alemães e italianos. A região também possui população autóctone formada por indígenas e caboclos que, devido ao processo de colonização, ficou diluída dentro do conjunto total da população, vivendo em condições mais precárias. A partir da década de 1970, a agricultura familiar da região permitiu uma evolução econômica acelerada através do setor agroindustrial, que implicou intensa degradação dos recursos naturais, notadamente o desmatamento das florestas nativas.

Coleta de dados - Os métodos de coleta de dados basearam-se numa integração de métodos qualitativos e quantitativos em Etnobotânica. Foram realizadas entrevistas, entre os meses de janeiro e setembro de 2007, com agricultores familiares do município de Anchieta escolhidos por amostragem intencional (Tongco 2007). Esse tipo de amostragem permitiu que alguns critérios sócio-ambientais importantes para a pesquisa fossem atendidos, como amostras nas diversas comunidades rurais do município, na área de ocorrência da Floresta Estacional Decidual e da Floresta Ombrófila Mista, de homens e mulheres, de agricultores de duas faixas de idade mais de 40 anos e menos de 40 anos, e de diversas origens étnicas. Para outras variáveis procurou-se manter a casualidade durante a amostragem.

Utilizou-se um roteiro de entrevista semi-estruturado, com questões relacionadas à caracterização sócio-econômica do agricultor e da unidade de produção familiar, além de Listagem Livre (Bernard 1995) de espécies florestais nativas conhecidas pelos informantes. Durante essas entrevistas, também foram feitas perguntas sobre a utilidade das plantas citadas, sobre a origem desse conhecimento e sobre o uso das plantas pelos informantes para autoconsumo ou obtenção de renda (comércio), atual (últimos três anos) e no passado (de cinco anos para trás), visto que nos últimos anos aumentou muito a atenção sobre a degradação e a conservação de florestas nativas, o que pode influenciar no uso desses recursos. Neste trabalho, os 


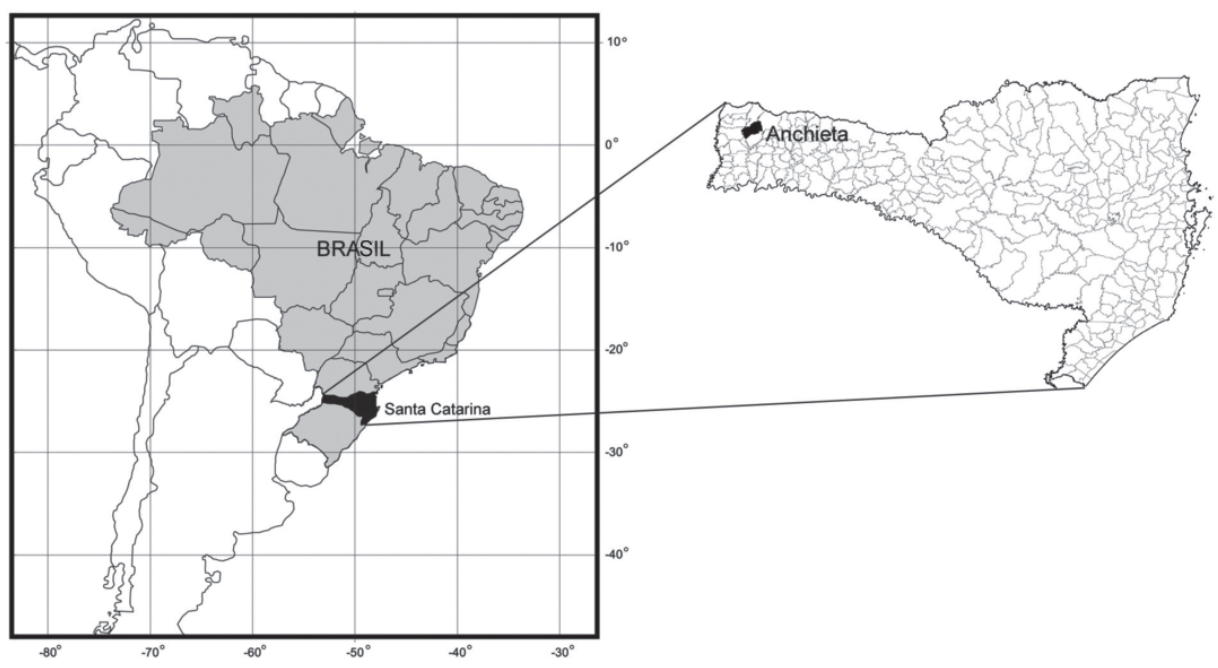

Figura 1. Localização do município de Anchieta no estado de Santa Catarina, Brasil.

usos de autoconsumo referem-se à utilização das espécies nativas na unidade de produção familiar, como por exemplo, em construções de residências, uso de plantas medicinais pela família, em estruturas e artefatos ligados à produção agropecuária, dentre outros.

Durante os eventos de entrevistas pôde-se fazer Observação Direta (Chizzotti 2006) do uso de recursos florestais nativos e seu emprego nas unidades de produção agropecuárias.

Foram realizadas também Turnês Guiadas (Alexiades 1996) nos fragmentos de florestas nativas das unidades de produção, quando os informantes foram questionados novamente a respeito da utilização atual das espécies florestais, seu abandono e substituição por outros tipos de recursos, e os fatores associados.

Os procedimentos para o consentimento prévio informado preconizados pelo Conselho de Gestão do Patrimônio Genético (CGEN) para a realização da pesquisa foram realizados em reuniões com instituições locais ligadas aos agricultores familiares de Anchieta, em assembléia de agricultores familiares e durante cada entrevista.

Análise dos dados - A identificação botânica das plantas foi feita com auxílio de bibliografia (Flora Ilustrada Catarinense; Lorenzi \& Matos 2002; Souza \& Lorenzi 2005; Marchiori 1997; Backes \& Irgang 2002) e de especialistas. As espécies identificadas foram agrupadas em famílias botânicas de acordo com Souza \& Lorenzi (2005), baseado no sistema proposto pelo Angiosperm Phylogeny Group II (APGII) (2003).

As espécies foram classificadas pelos autores do artigo, baseado no trabalho de Hanazaki et al. (2006), nas seguintes categorias de uso, de acordo com os usos citados nas entrevistas: alimentício, artefato, combustível, construção, forragem, medicinal, ornamental, tóxica e outros. Cada espécie pôde ser classificada em mais de uma categoria, visto que foram citados diversos usos para cada espécie e foi considerado que apenas uma citação de uso referente a uma categoria, era suficiente para assim classificá-la.

Foi calculada a "Importância de Uso" (IU), um índice de consenso que procura verificar a concordância entre informantes (Kainer \& Duryea 1992) a partir dos usos conhecidos das espécies. Esse índice é calculado a partir da relação $\mathrm{Ne} / \mathrm{NT}$ onde, Ne é o número de citações de uma espécie para um determinado uso e Nt é o número total de citações da espécie (Kainer \& Duryea 1992).

A comparação entre o número de citações de espécies para usos de autoconsumo, atual e passado, foi feita por teste qui-quadrado (Beiguelman 2002). Comparações entre usos de autoconsumo no passado e atual, para cada uma das categorias de uso, foram feitas através do teste nãoparamétrico de Wilcoxon (Siegel 1975) utilizando-se o software BioEstat 3.0 (Ayres et al. 2003).

A diversidade de citações de espécies florestais nativas, agrupados em classes de idade (acima e abaixo de 40 anos), foi expressa pelo índice de diversidade de Shannon-Wiener $\left(H^{\prime}\right)$ e pelo Índice de diversidade de
Simpson (D) (Begossi 1996; Magurran 1988). Os índices de diversidade foram comparados através de análise de rarefação por meio do software Ecosim (Gotelli \& Entsminger 2004). Para comparar a riqueza de espécies conhecidas, considerando o número de informantes agrupados em classes de idade (acima e abaixo de 40 anos), foram construídas curvas de rarefação e suas respectivas curvas de intervalo de confiança (95\% superior e $95 \%$ inferior) por meio do software Estimates 7.5 (Colwell 2005).

Em levantamentos de campo é importante a distinção entre conhecimento e uso de plantas, já que nem sempre esses dois parâmetros possuem uma relação direta (Monteiro et al. 2006). Frequentemente, o número de plantas conhecidas é maior do que o número de plantas utilizadas e a correlação entre essas variáveis pode ser influenciada por fatores sociais, econômicos e culturais (Ladio \& Lozada 2004; Amorozo 2004; Reyes-Garcia et al. 2005). Para verificar a correlação entre conhecimento e uso das espécies florestais nativas foi calculado o coeficiente de correlação de Spearman (Siegel 1975) para todos os informantes e para os informantes agrupados em classes de idade, considerando usos atual e passado de forma separada.

\section{Resultados e discussão}

Caracterização dos informantes e seu conhecimento a respeito das espécies florestais nativas - Foram entrevistados 42 agricultores individualmente, apenas um por unidade familiar de produção, pertencentes a 23 comunidades rurais de Anchieta. Os informantes possuem idades entre 19 e 76 anos (média $=48$ anos, d.p. $=17$ anos), 28 são homens e 14 mulheres, sendo $54 \%$ descendentes de italianos, $17 \%$ descendentes de alemães, $9 \%$ que se designam como "brasileiros" (caboclos) e os demais informantes são oriundos da miscigenação das diversas etnias presentes na região. A maioria dos agricultores entrevistados (63\%) cursou somente quatro anos do ensino oficial. As famílias são compostas em média por 3,6 pessoas morando na unidade familiar (d.p. $=1,4$ pessoas).

Foram identificadas entre as plantas coletadas nas entrevistas, 132 espécies, além de quatro plantas identificadas em nível de gênero, pertencentes a 51 famílias botânicas (Tab. 1). Foram citadas em média 29 espécies por informante (d.p. $=16$ espécies) e dentre as espécies identificadas 105 são de hábito arbóreo, 20 arbustivas, 6 trepadeiras e 4 são herbá- 
Tabela 1. Espécies florestais nativas conhecidas por 42 agricultores familiares do município de Anchieta/SC, suas denominações locais, respectivas famílias, hábito, número de citações, usos e seus respectivos índices de Importância de Uso (IU).

\begin{tabular}{|c|c|c|c|c|}
\hline FAMÍLIA / Espécies botânicas & Etnoespécie & Hábito & Citações & Usos e Importância de Uso (IU) \\
\hline \multicolumn{5}{|l|}{ ACHATOCARPACEAE } \\
\hline Achatocarpus praecox Griseb. & quebra-machado & arbustiva & 3 & Lenha (1), fruto $\mathrm{p}$ / pássaros $(0,3)$ \\
\hline \multicolumn{5}{|l|}{ ADOXACEAE } \\
\hline Sambucus australis Cham. \& Schltdl. & sabugueiro & arbórea & 8 & $\begin{array}{l}\text { Estufamento do gado }(0,3) \text {, febre }(0,2) \text {, lavar ferida } \\
(0,2) \text {, infecção úbero }(0,2)\end{array}$ \\
\hline \multicolumn{5}{|l|}{ ANACARDIACEAE } \\
\hline Schinus terebinthifolia Raddi & aroeira & arbórea & 3 & Sem uso (1) \\
\hline \multicolumn{5}{|l|}{ ANNONACEAE } \\
\hline Annona cacans Warm. & araticum & arbórea & 15 & Frutos $\mathrm{p} /$ comer $(1)$, lenha $(0,2)$ \\
\hline Rollinia sp. & araticum & arbórea & 5 & Frutos $\mathrm{p} /$ comer $(1)$, lenha $(0,2)$ \\
\hline \multicolumn{5}{|l|}{ APOCYNACEAE } \\
\hline Aspidosperma parvifolium A. DC. & $\begin{array}{l}\text { guatambú-amarelo, } \\
\text { piquiá }\end{array}$ & arbórea & 13 & $\begin{array}{l}\text { Madeira serrada }(0,4) \text {, lenha }(0,2) \text {, assoalho }(0,2) \text {, } \\
\text { móveis }(0,2)\end{array}$ \\
\hline Rauvolfia sellowii Müll. Arg. & $\begin{array}{l}\text { pau-amargo, bom(pau)- } \\
\text { pra-tudo }\end{array}$ & arbórea & 2 & Cólica na barriga $(0,5)$, sem uso $(0,5)$ \\
\hline \multicolumn{5}{|l|}{ AQUIFOLIACEAE } \\
\hline Ilex brevicuspis Reissek & caúna & arbórea & 1 & Madeira (1), lenha (1) \\
\hline Ilex paraguariensis A. St.-Hil. & erva-mate & arbórea & 3 & Chimarrão (1), tinta e cola $(0,3)$ \\
\hline \multicolumn{5}{|l|}{ ARACEAE } \\
\hline Philodendron bipinnatifidum Schott ex Endl. & banana-de-bugre & herbácea & 2 & Sem uso (1) \\
\hline \multicolumn{5}{|l|}{ ARALIACEAE } \\
\hline Schefflera angustissima (Marchal) Frodin & caxeta & arbórea & 3 & Madeira $(0,7)$, remédio $\mathrm{p} /$ coluna $(0,3)$ \\
\hline Aralia warmingiana (Marchal) J. Wen & cinamomo-do-mato & arbórea & 2 & Madeira $(0,5)$, sem uso $(0,5)$ \\
\hline \multicolumn{5}{|l|}{ ARAUCARIACEAE } \\
\hline Araucaria angustifolia (Bertol.) Kuntze & pinheiro & arbórea & 18 & Madeira serrada $(0,9)$, pinhão $(0,4)$ \\
\hline \multicolumn{5}{|l|}{ ARECACEAE } \\
\hline Syagrus romanzoffiana (Cham.) Glassman & coqueiro & arbórea & 6 & $\begin{array}{l}\text { Frutos } \mathrm{p} / \text { comer }(0,3) \text {, frutos } \mathrm{p} / \text { animais }(0,3) \text {, folhas } \\
\mathrm{p} / \text { cobrir galpão de fumo }(0,2)\end{array}$ \\
\hline \multicolumn{5}{|l|}{ ARISTOLOCHIACEAE } \\
\hline Aristolochia sp. & cipó-mil-homens & trepadeira & 4 & $\begin{array}{l}\text { Colocar no chimarrão }(0,5) \text {, problemas de coluna } \\
(0,25) \text {, gripe }(0,25) \text {, cólica }(0,25)\end{array}$ \\
\hline \multicolumn{5}{|l|}{ ASTERACEAE } \\
\hline Baccharis dracunculifolia DC. & vassoura-branca & arbustiva & 4 & Lenha $(0,8)$ \\
\hline $\begin{array}{l}\text { Baccharidastrum triplinervium (Less.) } \\
\text { Cabrera }\end{array}$ & $\begin{array}{l}\text { vassorinha, erva-de- } \\
\text { santana }\end{array}$ & arbustiva & 3 & Melífera $(0,7)$ \\
\hline \multicolumn{5}{|l|}{ BIGNONIACEAE } \\
\hline Jacaranda puberula Cham. & caroba & arbórea & 9 & $\begin{array}{l}\text { Madeira serrada }(0,4) \text {, móveis }(0,3) \text {, lavar feridas } \\
(0,3) \text {, sombra }(0,2)\end{array}$ \\
\hline Pyrostegia venusta (Ker Gawl.) Miers & cipó-de-são-joão & trepadeira & 4 & Medicinal $(0,8)$, ornamental $(0,3)$ \\
\hline $\begin{array}{l}\text { Tabebuia chrysotricha (Mart. ex A. DC.) } \\
\text { Standl. }\end{array}$ & ipê-amarelo & arbórea & 3 & $\begin{array}{l}\text { Madeira serrada }(0,3) \text {, chá da casca } \mathrm{p} / \text { dores }(0,3) \text {, } \\
\text { ornamental }(0,3)\end{array}$ \\
\hline Tabebuia heptaphylla (Vell.) Toledo & ipê-roxo & arbórea & 5 & $\begin{array}{l}\text { Roda de carroça }(0,4) \text {, madeira serrada }(0,4) \text {, chá } \\
\text { medicinal }(0,4)\end{array}$ \\
\hline \multicolumn{5}{|l|}{ BORAGINACEAE } \\
\hline Patagonula americana $\mathrm{L}$. & guajuvira & arbórea & 26 & $\begin{array}{l}\text { Palanque de cerca }(0,8) \text {, cabo de ferramenta }(0,3) \text {, } \\
\text { assoalho }(0,2)\end{array}$ \\
\hline Cordia trichotoma (Vell.) Arráb. ex Steud. & louro-preto & arbórea & 27 & $\begin{array}{l}\text { Madeira serrada }(0,8) \text {, palanque de cerca }(0,2) \text {, } \\
\text { aberturas, portas e janelas }(0,2)\end{array}$ \\
\hline
\end{tabular}


Tabela 1. Continuação

\begin{tabular}{|c|c|c|c|c|}
\hline FAMÍLIA / Espécies botânicas & Etnoespécie & Hábito & Citações & Usos e Importância de Uso (IU) \\
\hline Cordia ecalyculata Vell. & pau-de-bugre & arbórea & 1 & Sem uso (1) \\
\hline \multicolumn{5}{|l|}{ BROMELIACEAE } \\
\hline Bromelia balansae $\mathrm{Mez}$ & gravatá, caraguatá & herbácea & 2 & Xarope $(1)$, cataplasma $(0,5)$ \\
\hline \multicolumn{5}{|l|}{ CANNABACEAE } \\
\hline Celtis iguanaea (Jacq.) Sarg. & esporão-de-galo & arbustiva & 11 & $\begin{array}{l}\text { Frutos } p / \text { comer }(0,6), \text { lenha }(0,5), \text { frutos } p / \text { pássaros } \\
(0,4)\end{array}$ \\
\hline Trema micrantha (L.) Blume & grandiúva & arbórea & 4 & Gado come $(0,3)$, fazer pólvora $(0,3)$ \\
\hline \multicolumn{5}{|l|}{ CARDIOPTERIDACEAE } \\
\hline \multicolumn{5}{|l|}{ CARICACEAE } \\
\hline Vasconcella quercifolia A. St.-Hil. & mamãozinho-do-mato & arbórea & 3 & Frutos $\mathrm{p} /$ comer $(1)$ \\
\hline \multicolumn{5}{|l|}{ CELASTRACEAE } \\
\hline Maytenus muelleri Schwacke & $\begin{array}{l}\text { espinheira-santa, } \\
\text { cancorosa }\end{array}$ & arbórea & 8 & Lavar ferida $(0,3)$, limpar sangue $(0,3)$ \\
\hline \multicolumn{5}{|l|}{ DICKSONIACEAE } \\
\hline Dicksonia sp. & xaxim & arborescente & 1 & Ornamental e vaso (1) \\
\hline \multicolumn{5}{|l|}{ DIOSCORIACEAE } \\
\hline Dioscorea multiflora Griseb. & salsaparrilha & trepadeira & 1 & Sem uso (1) \\
\hline \multicolumn{5}{|l|}{ EUPHORBIACEAE } \\
\hline Alchornea triplinervia (Spreng.) Müll. Arg. & amorão, folha-de-bolo & arbórea & 3 & $\begin{array}{l}\text { Frutos } \mathrm{p} / \text { pássaros }(0,3), \text { madeira } \mathrm{p} / \text { local abrigado } \\
(0,3)\end{array}$ \\
\hline Gymnanthes concolor (Spreng.) Müll. Arg. & laranjeira-do-mato & arbórea & 10 & Lenha $(0,9)$, espeto $\mathrm{p} /$ assar carne $(0,1)$ \\
\hline Sapium glandulosum (L.) Morong & leiteiro & arbustiva & 2 & Sem uso (1) \\
\hline Sebastiania brasiliensis Spreng. & leiteiro & arbórea & 3 & Lenha $(0,7)$, matar berne $(0,3)$ \\
\hline $\begin{array}{l}\text { Sebastiania commersoniana (Baill.) L.B. } \\
\text { Sm. \& Downs }\end{array}$ & branquilho & arbórea & 4 & Lenha (1), palanque de cerca $(0,3)$ \\
\hline \multicolumn{5}{|l|}{ FABACEAE-CAESALPINIOIDEAE } \\
\hline Apuleia leiocarpa (Vogel) J.F. Macbr. & grápia & arbórea & 12 & $\begin{array}{l}\text { Madeira serrada }(0,7) \text {, palanque de cerca }(0,3) \text {, } \\
\text { assoalho }(0,2)\end{array}$ \\
\hline Gleditsia amorphoides (Griseb.) Taub. & coronilho & arbórea & 5 & Palanque de cerca $(1)$, lenha $(0,2)$ \\
\hline Holocalyx balansae Micheli & alecrim & arbórea & 16 & $\begin{array}{l}\text { Palanque de cerca }(0,7) \text {, lenha }(0,6) \text {, madeira serrada } \\
(0,3)\end{array}$ \\
\hline Peltophorum dubium (Spreng.) Taub. & canafístula & arbórea & 7 & Madeira serrada (1), lenha $(0,1)$ \\
\hline Senna tropica (Vell.) H.S. Irwin \& Barneby & mamica-de-cadela & arbórea & 2 & Madeira $\mathrm{p} /$ locais abrigados $(0,5)$, sem uso $(0,5)$ \\
\hline \multicolumn{5}{|l|}{ FABACEAE - CERCIDEAE } \\
\hline $\begin{array}{l}\text { Bauhinia forficata subsp. pruinosa (Vogel) } \\
\text { Fortunato \& Wunderlin }\end{array}$ & pata-de-vaca & arbórea & 16 & $\begin{array}{l}\text { Tratar problemas de rins }(0,4) \text {, problemas de bexiga } \\
(0,3) \text {, lenha }(0,3)\end{array}$ \\
\hline \multicolumn{5}{|l|}{ FABACEAE - FABOIDEAE } \\
\hline Dalbergia frutescens (Vell.) Britton & canela-do-brejo & arbórea & 7 & Canga de boi (1), madeira serrada $(0,4)$ \\
\hline Erythrina falcata Benth. & corticeira & arbórea & 4 & Laminação $(0,5)$, calçados $(0,3)$ \\
\hline Lonchocarpus campestris Mart. ex Benth. & rabo-de-bugio & arbórea & 13 & $\begin{array}{l}\text { Madeira serrada }(0,6) \text {, lenha }(0,5) \text {, canzil }(0,1) \text {, } \\
\text { carroceria de caminhão }(0,1)\end{array}$ \\
\hline Lonchocarpus subglaucescens Mart. ex Benth. & nogueira-do-mato & arbórea & 2 & Cesto $(1)$, madeira serrada $(0,5)$ \\
\hline Machaerium paraguariensis Hassl. & canela-do-brejo & arbórea & 8 & Canga de boi $(0,9)$, lenha $(0,3)$ \\
\hline Machaerium nyctitans (Vell.) Benth. & guampa-de-bode & arbórea & 1 & Lenha (1) \\
\hline Machaerium stipitatum (DC.) Vogel & $\begin{array}{l}\text { canela-do-brejo, farinha- } \\
\text { seca }\end{array}$ & arbórea & 14 & Lenha $(0,8)$, canga de boi $(0,4)$, cabeçalho de carroça $(0,2)$ \\
\hline Myrocarpus frondosus Allemão & cabreúva & arbórea & 26 & $\begin{array}{l}\text { Madeira serrada }(0,9) \text {, assoalho }(0,3) \text {, palanque de } \\
\text { cerca }(0,2) \text {, engenho de cana }(0,1)\end{array}$ \\
\hline
\end{tabular}


Tabela 1. Continuação

\begin{tabular}{|c|c|c|c|c|}
\hline FAMÍLIA / Espécies botânicas & Etnoespécie & Hábito & Citações & Usos e Importância de Uso (IU) \\
\hline \multicolumn{5}{|l|}{ FABACEAE - MIMOSOIDEAE } \\
\hline Acacia nitidifolia Speg. & unha-de-gato preta & trepadeira & 4 & Lenha $(0,3)$, problema de bexiga $(0,3)$, melífera $(0,3)$ \\
\hline Acacia recurva Benth. & unha-de-gato, japindá & trepadeira & 6 & Melífera $(0,5)$, sem uso $(0,3)$, problemas nos rins $(0,2)$ \\
\hline Albizia austrobrasilica Burkart & angico-branco & arbórea & 1 & Ornamental (1) \\
\hline Calliandra foliolosa Benth. & angiquinho cabelo-de-anjo & arbórea & 7 & Lenha $(0,6)$, ornamental $(0,3)$ \\
\hline Calliandra tweediei Benth. & angiquinho cabelo-de-anjo & arbórea & 2 & Ornamental (1) \\
\hline Inga marginata Willd. & angá miúdo & arbórea & 9 & Frutos p/ comer $(1)$, lenha $(0,4)$ \\
\hline Inga vera subsp. affinis (DC.) T.D. Penn. & angá graúdo & arbórea & 3 & Fruto $\mathrm{p}$ / comer $(0,7)$, madeira $(0,3)$, lenha $(0,3)$ \\
\hline $\begin{array}{l}\text { Enterolobium contortisiliquum (Vell.) } \\
\text { Morong }\end{array}$ & timbaúva & arbórea & 9 & $\begin{array}{l}\text { Madeira serrada }(0,9) \text {, caico (canoa) }(0,2) \text {, gamela } \\
(0,1)\end{array}$ \\
\hline Parapiptadenia rigida (Benth.) Brenan & angico-vermelho & arbórea & 25 & $\begin{array}{l}\text { Madeira serrada }(0,8) \text {, lenha }(0,6) \text {, palanque de cerca } \\
(0,6) \text {, assoalho }(0,1) \text {, casca medicinal }(0,1)\end{array}$ \\
\hline \multicolumn{5}{|l|}{ LAMIACEAE } \\
\hline Aegiphila brachiata Vell. & peloteiro & arbustiva & 1 & Sem uso (1) \\
\hline Ocimum selloi Benth & gervão & arbustiva & 1 & Chá (1) \\
\hline \multicolumn{5}{|l|}{ LAURACEAE } \\
\hline Nectandra megapotamica (Spreng.) Mez & canela-preta & arbórea & 11 & $\begin{array}{l}\text { Madeira serrada }(1) \text {, lenha }(0,3) \text {, tabuinha }(0,1) \text {, } \\
\text { palanque de cerca }(0,1)\end{array}$ \\
\hline Nectandra membranacea (Sw.) Griseb. & canela-loura, canela-pinha & arbórea & 11 & Madeira serrada (1), lenha $(0,2)$ \\
\hline Ocotea diospyrifolia (Meisn.) Mez & $\begin{array}{l}\text { canela-amarela, canela- } \\
\text { loura }\end{array}$ & arbórea & 8 & $\begin{array}{l}\text { Madeira serrada }(0,9) \text {, lenha }(0,3) \text {, móveis }(0,1) \text {, } \\
\text { marco de janela }(0,1)\end{array}$ \\
\hline Ocotea puberula (Rich.) Nees & canela, canela-pinha & arbórea & 21 & Madeira serrada $(0,9)$, lenha $(0,2)$, assoalho $(0,1)$ \\
\hline \multicolumn{5}{|l|}{ LOGANIACEAE } \\
\hline Strychnos brasiliensis (Spreng.) Mart. & pula-pula & arbórea & 4 & Dor de estômago $(0,3)$, rosário $(0,3)$, sem uso $(0,3)$ \\
\hline \multicolumn{5}{|l|}{ MALVACEAE } \\
\hline $\begin{array}{l}\text { Bastardiopsis densiflora (Hook. \& Arn.) } \\
\text { Hassl. }\end{array}$ & louro-branco & arbórea & 18 & $\begin{array}{l}\text { Madeira serrada }(0,8) \text {, lenha }(0,4), \text { madeira } \mathrm{p} / \text { locais } \\
\text { abrigados }(0,1)\end{array}$ \\
\hline Luehea divaricata Mart. & açoita-cavalo & arbórea & 24 & $\begin{array}{l}\text { Madeira serrada }(0,8) \text {, móveis }(0,3) \text {, remédio } \mathrm{p} / \text { vias } \\
\text { respiratórias }(0,1) \text {, canga de boi }(0,1)\end{array}$ \\
\hline \multicolumn{5}{|l|}{ MELIACEAE } \\
\hline Cabralea canjerana (Vell.) Mart. & canjerana & arbórea & 9 & Palanque para cerca $(1)$, madeira serrada $(0,4)$ \\
\hline Cedrela fissilis Vell. & cedro & arbórea & 16 & Madeira serrada $(0,8)$, móveis $(0,4)$ \\
\hline $\begin{array}{l}\text { Guarea macrophylla subsp. tuberculata } \\
\text { (Vell.) T.D. Penn. }\end{array}$ & puleiro-de-corvo & arbórea & 1 & Sem uso (1) \\
\hline Trichilia claussenii C. DC. & catiguá & arbórea & 4 & $\begin{array}{l}\text { Lenha }(1) \text {, palanque de cerca }(0,5) \text {, abrigo } \mathrm{p} / \text { abelha } \\
\text { mirim }(0,3)\end{array}$ \\
\hline Trichilia elegans A. Juss. & catiguá & arbustiva & 1 & Lenha (1) \\
\hline \multicolumn{5}{|l|}{ MONIMIACEAE } \\
\hline Hennecartia omphalandra Poiss. & erva-mate-do-mato & arbórea & 1 & Lenha (1) \\
\hline \multicolumn{5}{|l|}{ MORACEAE } \\
\hline Ficus insipida Willd. & figueira & arbórea & 3 & Sombra (1) \\
\hline Ficus monckii Hassl. & figueira & arbórea & 4 & Frutos p/ pássaros $(0,8)$, sombra $(0,5)$ \\
\hline Maclura tinctoria (L.) D. Don ex Steud. & tajuva & arbórea & 2 & Madeira serrada $(0,5)$, cabeçalho de carroça e arado $(0,5)$ \\
\hline $\begin{array}{l}\text { Sorocea bonplandii (Baill.) W.C. Burger, } \\
\text { Lanj. \& Wess. Boer }\end{array}$ & chincho & arbórea & 8 & $\begin{array}{l}\text { Cesto }(0,9) \text {, frutos } \mathrm{p} / \text { comer }(0,1), \text { arco de peneira } \\
(0,1)\end{array}$ \\
\hline \multicolumn{5}{|l|}{ MYRSINACEAE } \\
\hline Rapanea coriacea $(\mathrm{Sw}.) \mathrm{Mez}$ & pororoca & arbórea & 1 & Sem uso (1) \\
\hline Rapanea umbellata (Mart.) Mez & pororoca, caúna & arbórea & 1 & Madeira serrada (1) \\
\hline
\end{tabular}


Tabela 1. Continuação

\begin{tabular}{|c|c|c|c|c|}
\hline FAMÍLIA / Espécies botânicas & Etnoespécie & Hábito & Citações & Usos e Importância de Uso (IU) \\
\hline \multicolumn{5}{|l|}{ MYRTACEAE } \\
\hline $\begin{array}{l}\text { Campomanesia guazumifolia (Cambess.) } \\
\text { O. Berg }\end{array}$ & sete-capote & arbórea & 15 & $\begin{array}{l}\text { Frutos } p / \text { comer }(1), \text { lenha }(0,3) \text {, chá } p / \text { dor de barriga } \\
(0,1), \text { chá } p / \text { gripe }(0,1)\end{array}$ \\
\hline Campomanesia xanthocarpa O. Berg & guavirova & arbórea & 24 & Frutos $\mathrm{p} /$ comer $(1)$, lenha $(0,8)$, frutos $\mathrm{p} /$ animais $(0,2)$ \\
\hline $\begin{array}{l}\text { Eugenia burkartiana (D. Legrand) D. } \\
\text { Legrand }\end{array}$ & $\begin{array}{l}\text { primavera, jasmim-do- } \\
\text { mato }\end{array}$ & arbórea & 2 & Ornamental $(0,5)$, melífera $(0,5)$ \\
\hline Eugenia handroana D. Legrand & leiteiro-do-mato & arbórea & 1 & Sem uso (1) \\
\hline Eugenia involucrata DC & cereja, cerejeira & arbórea & 23 & Frutos $\mathrm{p} /$ comer $(0,9)$, lenha $(0,2)$, cabo de ferramenta $(0,1)$ \\
\hline Eugenia pyriformis Cambess. & uvaia, pêssego-do-mato & arbórea & 10 & Frutos $\mathrm{p} /$ comer $(0,9)$, frutos $\mathrm{p} /$ suco $(0,3)$, lenha $(0,2)$ \\
\hline Eugenia ramboi D. Legrand & batinga & arbórea & 3 & Lenha $(0,7)$, madeira serrada $(0,7)$, frutos $\mathrm{p} / \operatorname{comer}(0,3)$ \\
\hline Eugenia uniflora L. & pitanga & arbórea & 20 & $\begin{array}{l}\text { Frutos } p / \text { comer }(1) \text {, lenha }(0,4) \text {, medicinal }(0,1) \text {, } \\
\text { frutos } p / \text { pássaros }(0,1)\end{array}$ \\
\hline Gomidesia affinis (Cambess.) D. Legrand & sete-capote-do-mato & arbórea & 1 & Sem uso (1) \\
\hline Myrcianthes pungens (O. Berg) D. Legrand & guabijú & arbórea & 9 & Frutos para comer $(1)$, lenha $(0,3)$, palanque de cerca $(0,1)$ \\
\hline Myrciaria delicatula (DC.) Kausel & guamirim miúdo & arbórea & 1 & \\
\hline Plinia rivularis (Cambess.) A.D. Rotman & $\begin{array}{l}\text { batinga branca, } \\
\text { jabudiri, guapirú }\end{array}$ & arbórea & 4 & $\begin{array}{l}\text { Frutos p/ comer }(0,8) \text {, lenha }(0,5) \text {, cabeçalho de } \\
\text { carroça }(0,3)\end{array}$ \\
\hline Plinia trunciflora (O. Berg) Kausel & jaboticaba & arbórea & 9 & Frutos $\mathrm{p} /$ comer $(1)$ \\
\hline \multicolumn{5}{|l|}{ NYCTAGINACEAE } \\
\hline Pisonia ambigua Heimerl & carrapicho & arbórea & 1 & Sem uso (1) \\
\hline \multicolumn{5}{|l|}{ PHYTOLACCACEAE } \\
\hline Phytolacca dioica L. & ambuzeiro & arbórea & 14 & $\begin{array}{l}\text { Sem uso }(0,4) \text {, sombra }(0,3) \text {, combater pulga }(0,1) \text {, } \\
\text { frutos } \mathrm{p} \text { / gado comer }(0,1)\end{array}$ \\
\hline Seguieria guaranitica Speg. & limoeiro-do-mato & arbórea & 1 & Sem uso (1) \\
\hline \multicolumn{5}{|l|}{ PIPERACEAE } \\
\hline Piper amalago var. medium (Jacq.) Yunck. & jaguarandi & arbustiva & 2 & Gripe $(0,5)$, dor de garganta $(0,5)$ \\
\hline Piper gaudichaudianum Kunth & pariparova & arbustiva & 2 & Medicinal $(0,5)$, tumor $(0,5)$ \\
\hline Piper mikanianum var. mikanianum & pariparova, jaguarandi & arbustiva & 5 & $\begin{array}{l}\text { Gripe }(0,4) \text {, dor de garganta }(0,2) \text {, cicatrizante }(0,2) \text {, } \\
\text { infecções útero }(0,2)\end{array}$ \\
\hline \multicolumn{5}{|l|}{ POACEAE } \\
\hline Chusquea ramosissima Pilg. & criciúma & arbustiva & 2 & Alimentar animais $(0,5)$, varas $(0,5)$ \\
\hline Guadua spinosa (Swallen) McClure & taquaruçu & arbustiva & 1 & Palanque de cerca (1) \\
\hline Merostachys multiramea Hack. & taquara & arbustiva & 1 & Balaio (1) \\
\hline \multicolumn{5}{|l|}{ POLYGONACEAE } \\
\hline Ruprechtia laxiflora Meisn. & marmeleiro & arbórea & 2 & Madeira serrada (1) \\
\hline \multicolumn{5}{|l|}{ POLYPODIACEAE } \\
\hline Adiantum sp. & avenca & herbácea & 1 & Remédio para pulmão (1) \\
\hline Polypodium crassifolium L. & rabo-de-arara & herbácea & 1 & Sem uso (1) \\
\hline \multicolumn{5}{|l|}{ PROTEACEAE } \\
\hline $\begin{array}{l}\text { Roupala montana var. brasiliensis (Klotzsch) } \\
\text { K.S. Edwards }\end{array}$ & carvalho, caravagio & arbórea & 2 & Madeira serrada $(1)$, ornamental $(0,5)$ \\
\hline \multicolumn{5}{|l|}{ ROSACEAE } \\
\hline Rubus sellowii Cham. \& Schltdl. & amora-do-mato & arbustiva & 1 & Frutos $\mathrm{p} /$ comer $(1)$ \\
\hline $\begin{array}{l}\text { Prunus brasiliensis (Cham. \& Schltdl.) } \\
\text { Dietrich }\end{array}$ & pessegueiro-bravo & arbórea & 12 & $\begin{array}{l}\text { Folha murcha tóxica } \mathrm{p} / \text { gado }(0,6) \text {, madeira serrada } \\
(0,4) \text {, lenha }(0,2)\end{array}$ \\
\hline \multicolumn{5}{|l|}{ RUTACEAE } \\
\hline Balfourodendron riedelianum (Engl.) Engl. & guatambu, marfim & arbórea & 24 & $\begin{array}{l}\text { Madeira serrada }(0,8) \text {, lenha }(0,4) \text {, assoalho }(0,3) \text {, } \\
\text { cabo de ferramenta }(0,1)\end{array}$ \\
\hline Helietta longifoliata Britton & canela-de-veado & arbórea & 8 & $\begin{array}{l}\text { Lenha }(0,6) \text {, palanque de cerca }(0,4) \text {, madeira serrada } \\
(0,3) \text {, cabo de ferramenta }(0,1)\end{array}$ \\
\hline Pilocarpus pennatifolius Lem. & cotia, cotieira & arbórea & 8 & Lenha $(0,5)$, espeto $\mathrm{p} /$ assar carne $(0,1)$ \\
\hline
\end{tabular}


Tabela 1. Continuação

\begin{tabular}{|c|c|c|c|c|}
\hline FAMÍLIA / Espécies botânicas & Etnoespécie & Hábito & Citações & Usos e Importância de Uso (IU) \\
\hline Zanthoxylum naranjillo Griseb. & mamiqueira-miúda & arbórea & 1 & Madeira p/ locais abrigados (1) \\
\hline Zanthoxylum rhoifolium Lam. & mamica-de-cadela & arbórea & 8 & Lenha $(0,6)$, madeira serrada $(0,3)$, lâmina $(0,1)$ \\
\hline \multicolumn{5}{|l|}{ SALICACEAE } \\
\hline Casearia lasiophylla Eichler & guaçatonga & arbórea & 1 & Cabo de ferramenta (1) \\
\hline Casearia obliqua Spreng. & guaçatonga & arbórea & 1 & $\begin{array}{l}\text { Cabo de ferramenta (1), depurativa do sangue (1), } \\
\text { obesidade (1), cicatrizante (1) }\end{array}$ \\
\hline Casearia sylvestris Sw. & $\begin{array}{l}\text { guaçatonga, chá- } \\
\text { de-bugre }\end{array}$ & arbórea & 13 & $\begin{array}{l}\text { Alergia e desintoxicação }(0,2) \text {, cicatrizante }(0,1) \text {, } \\
\text { colesterol }(0,1) \text {, lavar cachorro com sarna }(0,1)\end{array}$ \\
\hline \multicolumn{5}{|l|}{ SAPINDACEAE } \\
\hline $\begin{array}{l}\text { Allophylus edulis (A. St.-Hil., Cambess. \& A. } \\
\text { Juss.) Radlk. }\end{array}$ & olho-de-pombo, vacum & arbórea & 7 & $\begin{array}{l}\text { Frutos } \mathrm{p} / \text { comer }(0,6), \text { lenha }(0,4), \text { frutos } \mathrm{p} / \text { pássaros } \\
(0,3), \text { chá medicinal }(0,1)\end{array}$ \\
\hline Cupania vernalis Cambess. & camboata-vermelho & arbórea & 12 & $\begin{array}{l}\text { Lenha }(0,6) \text {, madeira serrada }(0,3) \text {, tratar pressão } \\
\text { alta }(0,2)\end{array}$ \\
\hline Diatenopteryx sorbifolia Radlk. & maria-preta & arbórea & 11 & Lenha (1), madeira serrada $(0,2)$, melífera $(0,1)$ \\
\hline Matayba elaeagnoides Radlk. & camboata-branco & arbórea & 5 & Lenha $(0,8)$, madeira $(0,2)$ \\
\hline \multicolumn{5}{|l|}{ SAPOTACEAE } \\
\hline $\begin{array}{l}\text { Chrysophyllum gonocarpum (Mart. \& } \\
\text { Eichler ex Miq.) Engl. }\end{array}$ & $\begin{array}{l}\text { aguaí, desfolhador, } \\
\text { pororoca }\end{array}$ & arbórea & 5 & $\begin{array}{l}\text { Lenha }(0,6), \text { frutos } \mathrm{p} / \text { pássaros }(0,4), \text { frutos } \mathrm{p} / \text { comer } \\
(0,2)\end{array}$ \\
\hline $\begin{array}{l}\text { Chrysophyllum marginatum (Hook. \& Arn.) } \\
\text { Radlk. subsp. marginatum }\end{array}$ & vassorinha & $\begin{array}{l}\text { arbórea/ } \\
\text { arbustiva }\end{array}$ & 6 & Lenha $(0,8)$ \\
\hline \multicolumn{5}{|l|}{ SIMAROUBACEAE } \\
\hline Picrasma crenata (Vell.) Engl. in Engl. \& Prantl & pau-amargo & arbórea & 1 & Tratar dor de barriga (1) \\
\hline \multicolumn{5}{|l|}{ SOLANACEAE } \\
\hline Acnistus breviflorus Sendtn. & limão-do-mato & arbórea & 1 & Sem uso (1) \\
\hline Brunfelsia uniflora (Pohl) D. Don & primavera & arbustiva & 2 & Ornamental (1) \\
\hline Cestrum bracteatum Link \& Otto & mata-boi & arbórea & 8 & Folha murcha tóxica p/ gado $(0,8)$ \\
\hline Cestrum intermedium Sendtn. & peloteira & arbustiva & 1 & Frutos p/ pássaros (1) \\
\hline Solanum mauritianum Scop. & fumeiro-bravo & arbustiva & 6 & $\begin{array}{l}\text { Lenha }(0,3) \text {, sem uso }(0,3) \text {, tratar amarelão nas } \\
\text { criações }(0,2) \text {, frutos } \mathrm{p} / \text { pássaros }(0,2)\end{array}$ \\
\hline \multicolumn{5}{|l|}{ STYRACACEAE } \\
\hline Styrax leprosus Hook. \& Arn. & carne-de-vaca & arbórea & 11 & $\begin{array}{l}\text { Lenha }(0,4) \text {, madeira } \mathrm{p} \text { / locais abrigados }(0,4) \text {, forro } \\
(0,2) \text {, lâmina }(0,2) \text {, caixaria }(0,1)\end{array}$ \\
\hline \multicolumn{5}{|l|}{ TROPAEOLACEAE } \\
\hline Tropaeolum pentaphyllum Lam. & crem & trepadeira & 1 & Conserva (1) \\
\hline \multicolumn{5}{|l|}{ URTICACEAE } \\
\hline Boehmeria caudata Sw. & jaguarão-do-mato & arbustiva & 2 & Sem uso (1) \\
\hline Urera baccifera (L.) Gaudich. ex Wedd. & urtigão & arbustiva & 1 & Chá diurético (1) \\
\hline \multicolumn{5}{|l|}{ VERBENACEAE } \\
\hline Aloysia virgata (Ruiz \& Pav.) Pers. & cambará & arbórea & 9 & $\begin{array}{l}\text { Melífera }(0,4), \text { lenha }(0,3), \text { problemas vias } \\
\text { respiratórias }(0,2) \text {, dor de barriga }(0,1)\end{array}$ \\
\hline Vitex megapotamica (Spreng.) Moldenke & tarumã & arbórea & 5 & Palanque de cerca $(1)$, madeira serrada $(0,2)$ \\
\hline \multicolumn{5}{|l|}{ WINTERACEAE } \\
\hline Drimys brasiliensis Miers & casca-de-anta & arbórea & 1 & Condimento (1), vermífugo (1) \\
\hline
\end{tabular}

ceas (Tab. 1). As principais famílias botânicas encontradas foram Fabaceae (19 espécies), seguida por Myrtaceae (13 espécies) e outras famílias que se destacaram, mas que apresentaram menor número de espécies foram: Euphorbiaceae (5 espécies), Meliaceae (5 espécies), Rutaceae (5 espécies) e Solanaceae (5 espécies) (Tab. 1).

O conhecimento dos agricultores familiares de Anchieta abrange grande parte da diversidade de espécies arbóreas da
Floresta Estacional Decidual do estado de Santa Catarina, tipologia florestal que predomina no município, onde se estima uma composição de 181 espécies arbóreas (Reis 1993).

O número de espécies e o número de citações de espécies foram agrupados em categorias de uso, segundo o conhecimento dos informantes a respeito da utilidade das plantas (Fig. 2), destacando-se as categorias construção, combustível, alimentício, artefatos e medicinais. O conhecimento dos 


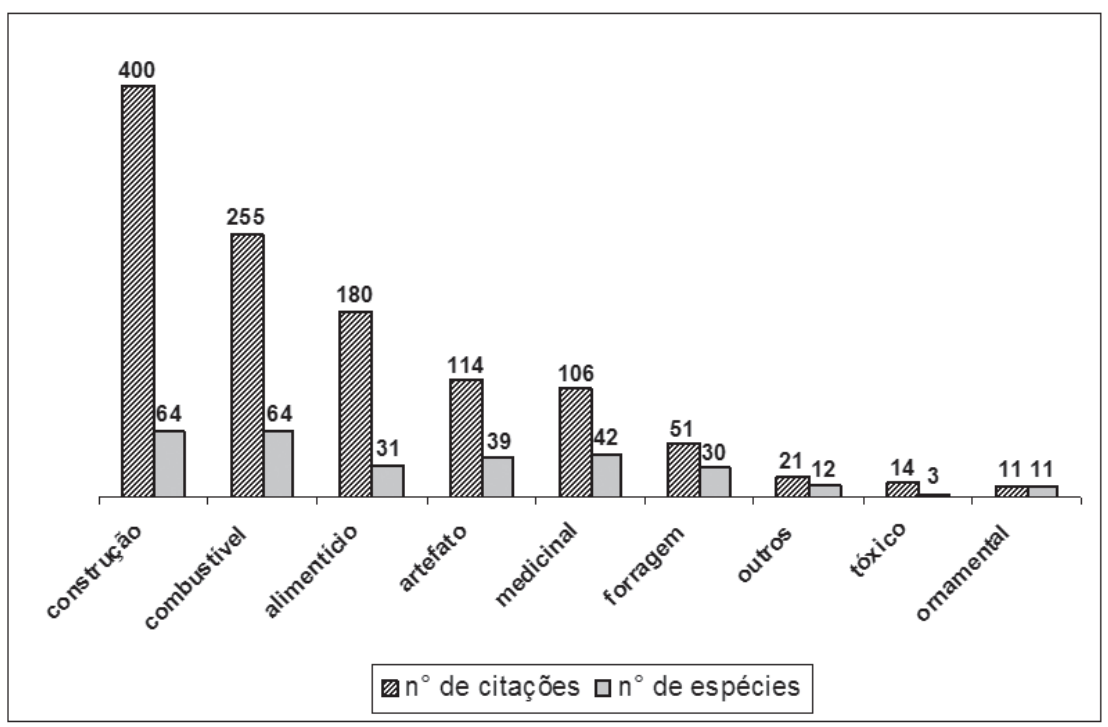

Figura 2. Número de espécies florestais nativas e número de citações por 42 agricultores familiares do município de Anchieta/SC, de acordo com as categorias de uso.

informantes a respeito das espécies florestais nativas, principalmente nas categorias de uso que mais se destacaram, está diretamente relacionado com usos cotidianos desses recursos e o modo de vida desses agricultores, como ocorre em outros trabalhos (p. ex. Albuquerque \& Andrade 2002; Hanazaki et al 2006), demonstrando a importância desses recursos nas estratégias de sobrevivência de populações rurais brasileiras.

$\mathrm{Na}$ categoria construção, o conhecimento está relacionado ao uso de madeira serrada ou em tora em construções e reformas de residências e em outras benfeitorias das unidades de produção; na categoria combustível o conhecimento se refere às espécies que possuem as melhores características para o uso como lenha para cozinhar e aquecer as residências no inverno; na categoria alimentícia destaca-se o conhecimento sobre os frutos comestíveis, e na categoria artefatos o conhecimento sobre o emprego de espécies florestais na confecção de utensílios destinados às atividades agrícolas, como arados, carroças, cangas de boi, cabos de ferramentas, dentre outros usos citados.

As condições ambientais da região, como a elevada pedregosidade do solo e declividade do relevo, impossibilitam a mecanização da agricultura na maior parte do município, sendo que apenas 10,5\% das unidades de produção possuem trator (IBGE, 2009b). A inexistência de alternativas disponíveis mantém a dependência desses agricultores ao uso das espécies florestais nativas para confecção de artefatos agrícolas de tração animal, baseado em um conhecimento especializado e adquirido ao longo de gerações.

Os informantes relataram que o conhecimento que possuem a respeito das espécies florestais nativas foi transmitido oralmente, através do ensinamento de seus pais, na maior parte dos casos, mas também no convívio com parentes (cônjuge, avós, sogros) e vizinhos, e em atividades profissionais em serrarias ou como mateiros.

Uso efetivo atual e passado das espécies florestais nativas - Durante as entrevistas foi feita distinção entre o conhecimento e o uso efetivo das espécies citadas pelos informantes, sendo analisado nesta seção apenas o uso efetivo. Uma análise do uso das espécies florestais nativas, atual e passado, de autoconsumo e comercial, é apresentada na Fig. 3 , através do agrupamento em categorias de uso.

O uso comercial não ocorre atualmente entre os informantes. No passado, ocorria a comercialização, porém com menor frequência que os usos de autoconsumo na mesma época (Fig. 3). No processo de colonização da região Oeste de Santa Catarina, a partir do início do século XX, a indústria madeireira teve forte atuação na região e fazia sua exploração em lotes de terra de empresas colonizadoras. A intensa atividade madeireira nesta época, segundo os informantes, facilitava a venda de madeira pelos agricultores familiares de Anchieta, mas a atividade não era muito expressiva para este grupo porque as florestas nativas na região eram abundantes.

De forma geral, houve redução significativa no uso atual de autoconsumo de espécies florestais nativas entre os informantes em relação ao mesmo tipo de uso no passado, como revela a comparação do número de citações de espécies $\left(X^{2}=30,3 ; G . L .=5 ; p<0,001\right)$. Quando é feita a comparação do uso atual de autoconsumo em relação ao passado dentro de cada categoria de uso, encontrou-se diferença significativa nas categorias construção $(z=4,25 ; p<0,0001)$, artefato $(z=3,3 ; p=0,001)$ e combustível $(z=2,76 ; p=0,006)$. Não houve diferença significativa nas categorias alimentício $(\mathrm{z}=0,51 ; \mathrm{p}=0,61)$ e medicinal $(\mathrm{z}=0,32 ; \mathrm{p}=0,75)$.

As categorias de uso em que se verificou redução no uso atual (construções, artefatos, combustível) estão fortemente relacionadas a usos madeireiros das espécies. A partir das entrevistas verificou-se que somente $18 \%$ dos informantes estão utilizando atualmente madeiras de espécies nativas em construções e reformas e $50 \%$ dos informantes estão substituindo as espécies nativas por espécies florestais exóticas para estes usos, cultivadas, na maioria dos casos, 


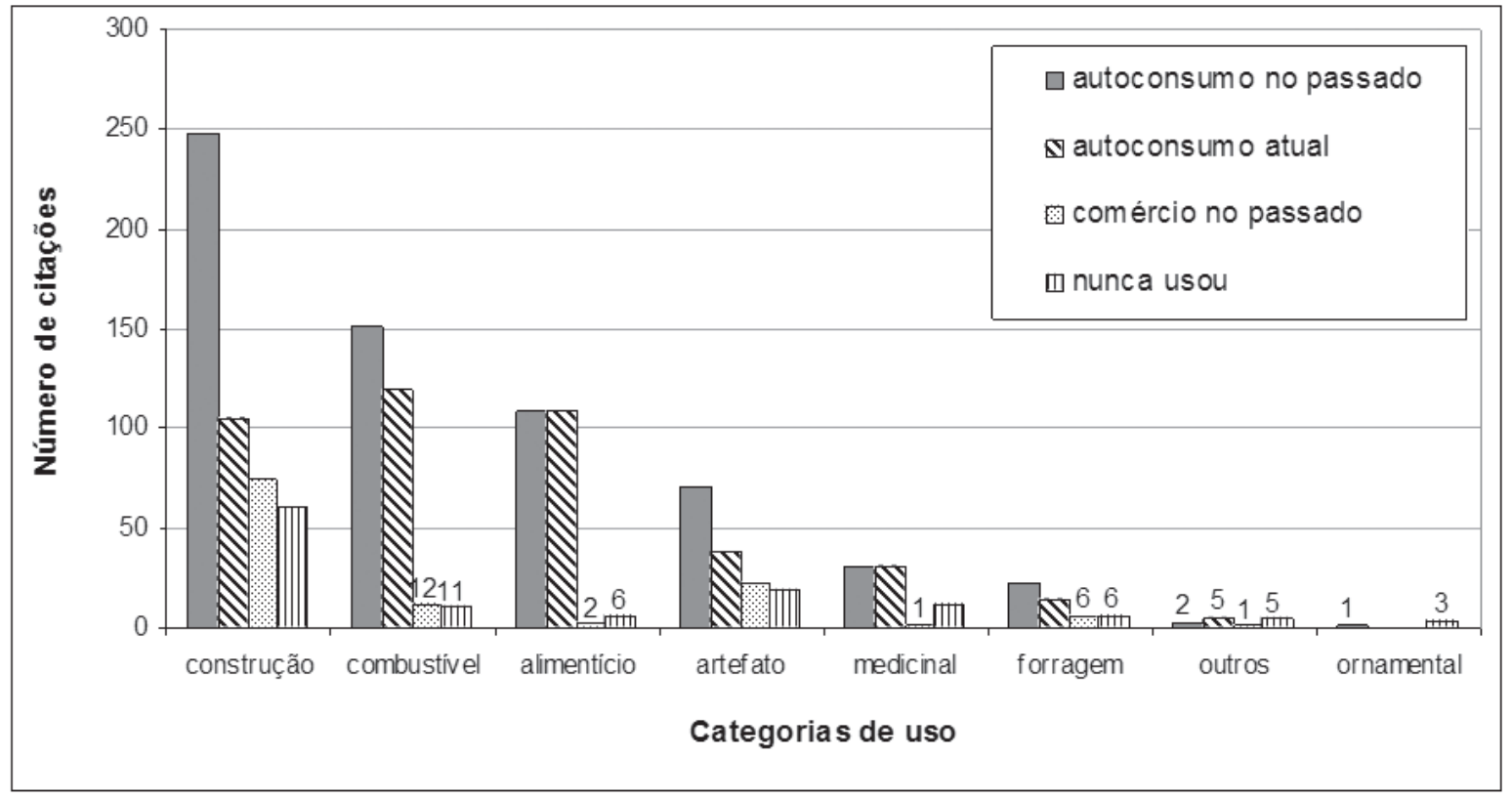

Figura 3. Número de citações de espécies florestais nativas por 42 agricultores familiares do município de Anchieta/SC, de acordo com as categorias de uso e tipos de uso (subsistência no passado, subsistência atual, comércio no passado e nunca usou).

na unidade de produção. O cultivo de espécies florestais exóticas ocorre, em alguns casos, em áreas abandonadas para cultivos agrícolas. Nestes casos, os informantes afirmaram que essas áreas são ocupadas para evitar a regeneração da floresta nativa, que lhes traria restrições para o uso futuro da terra e dos recursos, por conta da atual legislação ambiental.

Quando questionados sobre as razões para a substituição das espécies nativas madeireiras em construções, a maioria dos informantes $(58 \%$; $\mathrm{N}=21)$ fez referência às limitações relacionadas às leis ambientais que regulamentam esse tipo de uso. No estado de Santa Catarina a autorização para o corte seletivo de até 20 unidades (indivíduos) de árvores nativas ou até $15 \mathrm{~m}^{3}$ de galhada de árvores para lenha, permitida em unidades de produção com até 30 ha, exige a apresentação de projeto elaborado por um técnico, averbação de Reserva Legal na escritura do imóvel, planta topográfica georreferenciada do imóvel, entre outros documentos. Esses procedimentos representam custos elevados e burocracia para os agricultores familiares de Anchieta, caracterizando-se como fatores impeditivos para a utilização legal dos recursos.

Outros fatores citados para a substituição do uso das espécies nativas como madeira, estão relacionados à escassez de indivíduos de espécies nativas existentes nos pequenos fragmentos nas unidades de produção ( $14 \%$ dos informantes; $\mathrm{N}=21)$ e também o desejo de preservar os fragmentos remanescentes $(5 \%$ dos informantes; $\mathrm{N}=21$ ). Em casos mais extremos, informantes declararam que estão deixando de fazer reformas em benfeitorias das unidades de produção e em suas residências por não terem acesso legal à extração de madeira de espécies nativas existentes em seus fragmentos, o que, segundo estes informantes, representaria uma redução significativa nos custos dessas obras.
Apesar da redução significativa do número de citações de espécies utilizadas atualmente como combustível (lenha), $92 \%$ dos agricultores entrevistados utilizam lenha de espécies nativas, o que pôde ser verificado com freqüência nas residências dos informantes. $\mathrm{O}$ fogão a base de lenha é utilizado por $97 \%$ dos informantes, sendo o principal modo de cozinhar alimentos durante todo o ano para $71 \%$ deles, e no inverno esta percentagem se eleva para $90 \%$, já que este é o único meio de aquecimento das residências. A contradição verificada entre a atual redução do número de citações na categoria combustível e a grande dependência verificada entre os informantes para o uso espécies nativas para lenha, pode estar relacionada com uma possível redução no número de espécies utilizadas atualmente, devido ao uso preferencial das mais abundantes e a redução na diversidade de espécies disponíveis, o que precisa ser analisado com maior detalhamento em trabalhos futuros.

A manutenção do uso de espécies das categorias medicinal e alimentício entre os informantes, já que não houve diferença significativa entre o uso atual e passado nestas categorias, pode estar relacionado ao caráter esporádico, de pequena dimensão e não madeireiro desses tipos de usos, quando, em muitos casos, não é necessário o corte da planta inteira, não representando, portanto, como no caso dos usos madeireiros, restrição legal severa.

Conhecimento e correlação entre conhecimento e uso segundo a faixa etária - Os informantes com mais de 40 anos citaram um número maior de espécies $(\mathrm{N}=135)$ do que os entrevistados com menos de 40 anos ( $\mathrm{N}=99$ ), assim como fizeram maior número de citações em relação aos informantes com menos de 40 anos (Tab. 2). 
Tabela 2. Índices de diversidade de espécies florestais nativas conhecidas por agricultores familiares de Anchieta/SC, segundo a faixa etária.

\begin{tabular}{lcc}
\hline & \multicolumn{2}{c}{ Idade dos agricultores } \\
\cline { 2 - 3 } Número de informantes & Mais de 40 anos \\
Número de espécies & 25 \\
Número de citações (N) & $132 *$ \\
Índice de Shannon (H') & 801 \\
Índice de Simpson (D) & $4,52 *$ \\
\hline
\end{tabular}

* Diferença significativa considerando intervalo de confiança de $95 \%$.

Para os agricultores com mais de 40 anos, o índice de diversidade de Shannon das citações foi significativamente maior do que o calculado para os agricultores com menos de 40 anos (Tab. 2). Entre os informantes mais velhos foram encontrados valores menores do índice de Simpson (D), o que representa que existe entre estes informantes, uma distribuição mais equitativa de citações, pouco concentradas, enquanto que entre os informantes com menos de 40 anos existem uma distribuição menos equitativa, havendo uma concentração maior de citações de espécies por uma proporção menor de agricultores dentro da amostra.

Devido à diferença entre o número de informantes nos agrupamentos por idade, a comparação destes grupos em relação ao número de espécies citadas é mais bem avaliada utilizando-se curvas de rarefação e suas respectivas curvas de intervalo de confiança. Essa comparação mostrou que existe diferença significativa do número de espécies conhecidas entre os agricultores agrupados por faixa etária (Fig. 4). Durante as entrevistas, foi observado que alguns agricultores jovens reconheciam, por exemplo, um grupo de espécies como 'canelas' (diversas espécies dos gêneros Nectandra e Ocotea da família Lauraceae) mas não sabiam distinguir os diferentes "tipos", informação frequentemente conhecida entre agricultores mais velhos.

Essas diferenças entre faixas etárias podem estar relacionadas com a aquisição gradual ao longo da vida desse tipo de conhecimento (Phillips \& Gentry 1993). Estes autores apontam, por exemplo, que entre mestiços do sudeste do Peru o conhecimento sobre plantas para construção e destinadas ao comércio (incluindo plantas para extração de madeira e confecção de canoas) alcança seu auge entre 30 e 50 anos de idade. Entre comunidades tradicionais de caiçaras do litoral sudeste do Brasil, espécies nativas utilizadas para artefatos são mais conhecidas por pessoas com mais de 40 anos (Hanazaki et al. 2000). No entanto, pode-se considerar que o abandono do uso das espécies florestais nativas pode estar afetando a construção do conhecimento dos agricultores mais jovens.

Encontrou-se correlação positiva e significativa entre o número de espécies conhecidas e usadas pelos informantes (Tab. 3), no entanto, observou-se que os valores do coeficiente de Spearman (rs) são menores para usos atuais do que para usos no passado, principalmente para os informantes com menos de 40 anos, chegando, nesse caso, próximo ao nível crítico de significância $(\mathrm{P}=0,047)$ (Tab. 3). Ao comparar duas comunidades de mesma etnia na Amazônia Boliviana, Reyes-Garcia et al. (2005) verificaram que a comunidade mais distante do centro urbano conhecia e utilizava mais plantas e a correlação positiva e significativa entre essas variáveis só ocorreu nessa comunidade. Ladio \& Lozada (2004) encontraram que entre pessoas de comunidades Mapuche da Patagônia existe correlação positiva entre idade e conhecimento de espécies comestíveis das florestas Andinas, no entanto, a correlação entre idade e consumo não foi observada, o que se deve à remota localização destas florestas (mais que $50-70 \mathrm{Km}$ ).

As correlações entre conhecimento e uso de espécies florestais nativas encontradas entre os informantes indicam que atualmente, o conhecimento acumulado entre esses agricultores, principalmente entre os mais jovens, não corresponde ao efetivo uso das espécies. As limitações ao uso das espécies madeireiras nativas têm levado os agricultores, principalmente os mais jovens, a adotarem estratégias alternativas como o plantio e uso de espécies florestais exóticas.

Mudanças sócio-econômicas rápidas podem atenuar a correlação entre conhecimento e uso em curto prazo, e em longo prazo afetar o conhecimento etnobotânico (Reyes-Garcia et al. 2005). Portanto, os fatores apontados pelos informantes para a substituição ou abandono do uso das espécies nativas madeireiras, podem estar sendo os responsáveis pela atenuação da correlação entre conhecimento e uso atual, gerando um processo gradual de perda das condições de transmissão do conhecimento ecológico local. Mantidos os fatores apontados, pode ocorrer perda do conhecimento ecológico acumulado entre esses agricultores. Reyes-Garcia et al. (2005) ressaltam que a análise do abandono do uso de plantas pode substituir análises de longo prazo que visam identificar mudanças no nível de conhecimento etnobotânico.

Como o conhecimento tradicional se mantém pela prática cotidiana (Hunn 1999), sua conservação em Anchieta poderia ser possibilitada pela compatibilização do acesso legal simplificado às espécies florestais nativas relevantes ao modo de vida desses agricultores, e pela promoção e conservação das populações de espécies em remanescentes florestais das unidades de produção familiar. Neste senti- 


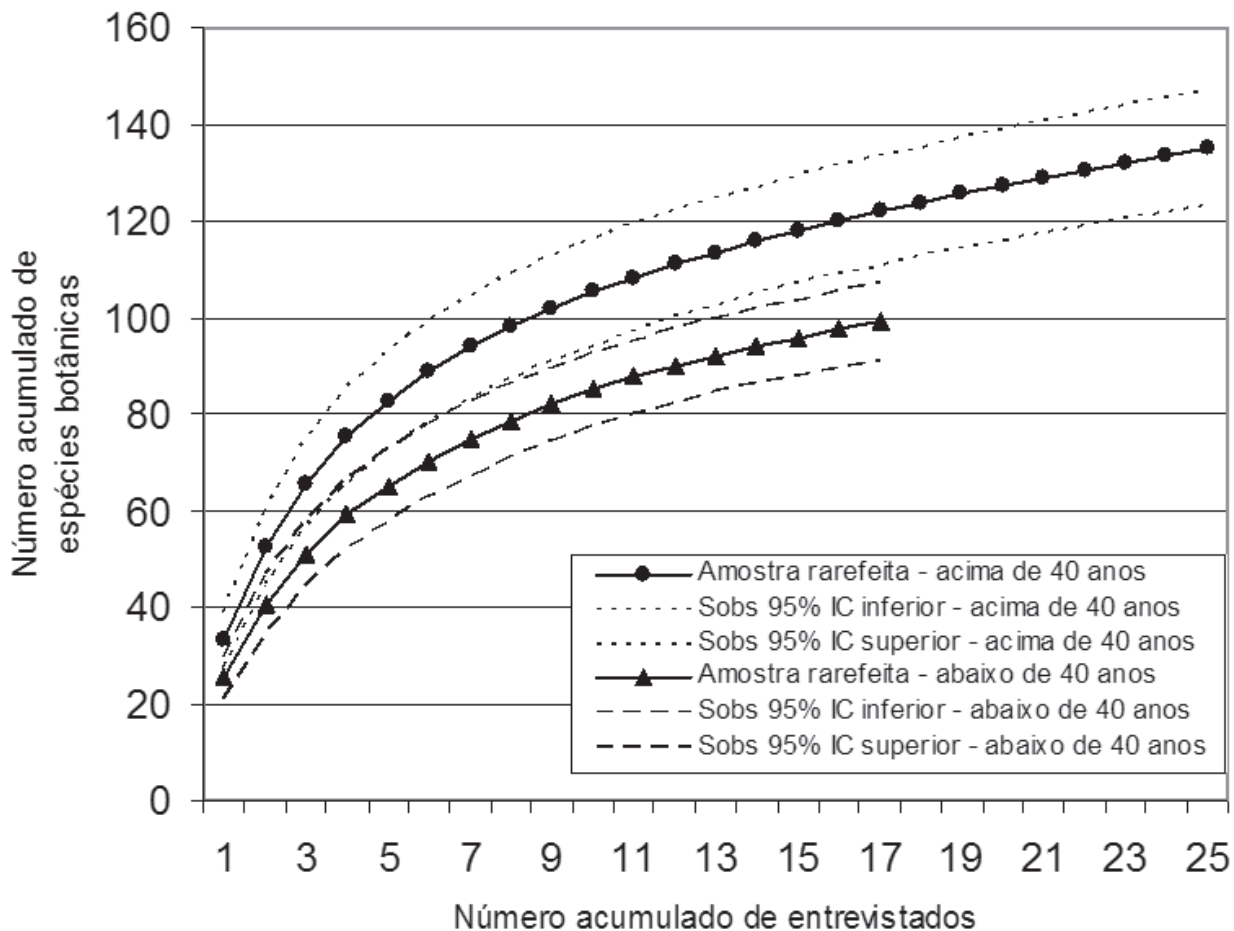

Figura 4. Curvas de acumulação rarefeitas de espécies florestais nativas citadas por 42 agricultores familiares do município de Anchieta/SC, agrupados por faixas etárias (abaixo e acima de 40 anos), com suas respectivas curvas de intervalo de confiança (95\% inferior e superior).

Tabela 3. Coeficientes de correlação de Spearman (rs) entre conhecimento e uso efetivo de espécies florestais nativas por agricultores familiares do município de Anchieta, Santa Catarina e probabilidade de significância (P).

\begin{tabular}{lccr}
\hline & Idade & Coeficiente de Spermam (rs) & P \\
\hline \multirow{3}{*}{ Uso no passado } & Todos & 0,79 & $<0,0001$ \\
& $>40$ anos & 0,77 & $<0,0001$ \\
& $<40$ anos & 0,80 & 0,0002 \\
\hline \multirow{2}{*}{ Uso atual } & Todos & 0,61 & $<, 0001$ \\
& $>40$ anos & 0,70 & 0,0001 \\
& $<40$ anos & 0,50 & 0,047 \\
\hline
\end{tabular}

do, uma revisão das políticas ambientais seria necessária, considerando estratégias integradas de conservação e uso de florestas nativas, a partir de conhecimentos científicos, tradicionais e locais e do envolvimento das comunidades rurais em seu planejamento e implementação (Fantini \& Siminski, 2007; Reis 2006).

\section{Agradecimentos}

Aos agricultores que participaram da pesquisa e instituições locais que nos apoiaram, ao CNPq (bolsa de mestrado e recursos para pesquisa) e CT-Hidro/MCT (recursos para pesquisa), ao Prof. Dr. Ademir Reis da Universidade Federal de Santa Catarina, a Prof. Dra. Roseli Bortoluzzi da Universidade do Estado de Santa Catarina e ao Museu Botânico do Jardim Botânico de Curitiba pela identificação botânica das plantas.

\section{Referências bibliográficas}

Alexiades, M.N. 1996. Collecting ethnobotanical data: an introduction to basic concepts and techniques. Pp. 53-94. In: Alexiades, M.N. (ed.). Selected guidelines for Ethnobotanical research: a field manual. New York, The New York Botanical Garden.

Alexiades, M.N. 2003. Ethnobotany in the Third Millennium: expectations and unresolved issues. Depinoa 45: 15-28.

Albuquerque, U.P. \& Andrade, L.H.C. 2002. Conhecimento botânico tradicional e conservação em uma área de caatinga no Estado de Pernambuco, Nordeste do Brasil. Acta Botanica Brasilica 16: 273285 .

Amorozo, M.C. de M. 2004. Pluralistic medical settings and medicinal plant use in rural communities, Mato Grosso, Brazil. Journal of Ethnobiology 24(1): 139-161.

Angiosperm Phylogeny Group II. 2003. An update of APG classification for the orders and families of flowering plants. Botanical Journal of the Linnean Society 141: 399-436. 
Ayres, M.; Ayres Jr., M.; Ayres, D. L. \& Santos, A. S. 2003. BioEstat 3.0. Aplicações estatísticas nas áreas das ciências biológicas e médicas. Belém, Sociedade Civil de Mamirauá.

Backes, P. \& Irgang, B. 2002. Árvores do Sul - Guia de identificação e interesse ecológico. Santa Cruz do Sul, Instituto Souza Cruz.

Baldauf, C.; Hanazaki, N. \& Reis, M. S. 2007. Caracterização etnobotânica dos sistemas de manejo de samambaia-preta (Rumohra adiantiformis (G.Forst) Ching - Dryopteridaceae) utilizados no sul do Brasil. Acta Botanica Brasilica 21: 823-834.

Beiguelman, B. 2002. Curso prático de bioestatística. Ribeirão Preto, Fundação de Pesquisas Científicas de Ribeirão Preto.

Begossi, A. 1996. Use of ecological methods in ethnobotany: diversity indices. Economic Botany 50(3): 280-289.

Benz, B.F.; Cevallos, J.; Santana, F.; Rosales, J. \& Graf, S. 2000. Losing knowledge about plant use in the sierra de Manantlan Biosphere Reserve, Mexico. Economic Botany 54:183-191.

Berkes, F.; Colding, J. \& Folke, C. 2000. Rediscovery of traditional ecological knowledge as adaptive management. Ecological Applications 10(5): 1251-1262.

Bernard, H.R. 1995. Research methods in anthropology: qualitative and quantitative approaches. Walnut Creek, Altamira Press.

Brumer, A.; Duque, G.; Lourenço, F.A. \& Wanderley, M.N.B. 1993. A exploração familiar no Brasil. Pp. 179-234. In: Lamarche, H. (coord.). A agricultura familiar: comparação internacional - uma realidade multiforme. Campinas, Ed. Unicamp.

Callon, M. 1986. Some elements of a sociology of translation: domestication of the scallops and fishermen of St. Brieuc Bay. In: LAW, J. (ed.). Power, action, belief: a new sociology of Knowledge? Londres: Routledge.

Chizzotti, A. 2006. Pesquisa em ciências humanas e sociais. São Paulo, Cortez.

Colwell, R.K. 2005. EstimateS: Statistical estimation of species richness and shared species form samples. Versão 7.5. Disponível em: http:// viveroy.eeb.uconn.edu/EstimateS.

Cunningham, A.B. 1996. Professional Ethics on Ethnobotanical Research. Pp. 19-52. In: Alexiades, M.N. Selected guidelines for Ethnobotanical research: a field manual. New York, The New York Botanical Garden.

Epagri/CEPA. 2007. Levantamento Agropecuário de Santa Catarina 2002-2003. Disponível em: <http://cepa.epagri.sc.gov.br>. Acesso em: 27 de janeiro de 2007.

Fantini, A.C. \& Siminski, A. 2007. De agricultor a "agricultor silvicultor": um novo paradigma para a conservação e uso de recursos florestais no Sul do Brasil. Agropecuária Catarinense 20(1):16-18.

Gadgil, M.; Berkes, F. \& Folke, C. 1993. Indigenous knowledge for biodiversity conservation. Ambio 22 (2-3): 151-156.

Godoy, R.; Brokaw, N.; Wilkie, D.; Colón, D.; Palermo, A.; Lye, S. \& Wei, S. 1998. Of trade and cognition: markets and the loss of folk knowledge among the Tawahka Indians of the Honduran rain forest. Journal of Anthropological Research 54(2): 219-233.

Gotelli, N.J. \& Entsminger, G.L. 2004. EcoSim: Null models software for ecology. Version 7. Acquired Intelligence Inc. \& Kesey-Bear. Jericho, VT 05465. Disponível em: http://garyentsminger.com/ecosim/index. htm. Acesso em agosto de 2009.

Guivant, J.S. 1997. Heterogeneidade de Conhecimentos no Desenvolvimento Rural Sustentável. Cadernos de Ciência e Tecnologia 14(3): 412-447.

Hanazaki, N.; Tamashiro, J.Y.; Leitão Filho, H.F. \& Begossi, A. 2000. Diversity of plant uses in two Caiçara communities from Atlantic Forest coast, Brazil. Biodiversity and Conservation 9:597-615.

Hanazaki, N. 2003. Comunidades, conservação e manejo: o papel do conhecimento ecológico local. Biotemas 16(1): 23-47.

Hanazaki, N.; Souza, V.C. \& Rodrigues, R.R. 2006. Ethnobotany of rural people from the boundaries of Carlos Botelho State Park, São Paulo State, Brazil. Acta Botanica Brasilica 20(4): 899-909.

Hunn, E.S. 1999. The value of subsistence for the future of the world. Pp. 23-36. In: Nazarea, V.D. (ed.). Ethnoecology: situated knowledge/ located lives. Arizona, The University of Arizona Press.

IBGE - Instituto Brasileiro de Geografia e Estatística. 1990. Geografia do Brasil. Região Sul. Rio de Janeiro, v.2.
IBGE - Instituto Brasileiro de Geografia e Estatística. 2009a. Cidades@. Disponível em: http://www.ibge.gov.br/cidadesat/topwindow.htm?1. Acesso em 16 fev. 2009.

IBGE - Instituto Brasileiro de Geografia e Estatística. 2009b. Censo Agropecuário 2006. Disponível em http://www.ibge.gov.br/cidadesat/ topwindow.htm?1. Acesso em 7 ago. 2009.

Kainer, K.A. \& Durea, M.L. 1992. Tapping women's knowledge: plant resource use in extractive reserves, Acre, Brazil. Economic Botany 46 (4): 408-425.

Ladio, A. \& M. Lozada. 2004. Patterns of use and knowledge of wild edible plants in distinct ecological environments: a case study of a Mapuche community from northwestern Patagonia. Biodiversity and Conservation 13:1153-1173.

Lorenzi, H \& Matos, F. J. A. 2002. Plantas medicinais no Brasil: nativas e exóticas. Nova Odessa, Instituto Plantarum.

Latour, B. 1987. Science in action: how to follow scientists and engineers through society. Cambridge: Harvard University Press.

Magurran, A. 1988. Ecological diversity and its measurement. London, Croom-Helm.

Marchiori, J. N. C. 1997. Dendrologia das angiospermas: das magnoliáceas às flacurtiáceas. Santa Maria, Editora da Universidade Federal de Santa Maria.

Monteiro, J.M.; Albuquerque, U.P..; Lins Neto, E.M.F.; Araújo, E.L. \& Amorim, E.L.C. 2006. Use patterns and knowledge of medicinal species among two rural communities in Brazil's semi-arid northeastern region. Journal of Ethnopharmacology 105: 173-186.

Neumann, P.S. \& Loch, C. 2002. Legislação ambiental, desenvolvimento rural e práticas agrícolas. Ciência Rural 32(2):243-249.

Peroni, N.; Begossi, A. \& Hanazaki, N. 2008. Artisanal fishers ethnobotany: from plant diversity use to agrobiodiversity management. Environment, Development and Sustainability 10:623-637.

Phillips, O. \& Gentry, A.H. 1993. The Useful Plants of Tamboapata, Peru: II. Additional Hypothesis Testing in Quantitative Ethnobotany. Economic Botany 47: 33-43.

Reis, A. 1993. Manejo e Conservação das Florestas Catarinenses (Trabalho apresentado para o Concurso de Professor Títular de Botânica Aplicada). Florianópolis, Universidade Federal de Santa Catarina.

Reis, M.S. 2006. Extrativismo no Sul e Sudeste do Brasil: Caminhos para a sustentabilidade socioambiental. Pp.117-128In: Kubo, R.R; Bassi, J.B.; Souza, G.C.; Alencar, N.L.; Medeiros, P.M. \& Albuquerque, U.P. (org.). Atualidades em Etnobiologia e Etnoecologia, Volume 3. NUPEEA/SBEE.

Reyes-García, V.; Vadez, V.; Huanca, T.; Leonard, W. \& Wilkie, D. 2005. Knowledge and uses of wild plants: A comparative study in two Tsimane' villages in the Bolivian lowlands. Ethnobotany Research \& Applications 3: 201-207.

Ruddle, K. 2000. Systems of knowledge: dialogue, relationships and process. Environment, Development and Sustainability 2: 277-304.

Siegel, S. 1975. Estatística não-paramétrica para as ciências do comportamento. São Paulo, McGraw-Hill.

Siminski, A. \& Fantini, A. C. 2007. Roça-de-toco: uso de recursos florestais e dinâmica da paisagem rural no litoral de Santa Catarina. Ciência Rural 37:01-10.

Siminski, A. 2009. A floresta do futuro : conhecimento, valorização e perspectivas de uso das formações florestais secundárias no Estado de Santa Catarina. Florianópolis, SC, Tese (Doutorado) Universidade Federal de Santa Catarina, Centro de Ciências Agrárias. Programa de Pós-Graduação em Recursos Genéticos Vegetais.

Souza, V. C. \& Lorenzi, H. 2005. Botânica Sistemática: guia ilustrado para identificação das famílias das angiospermas da flora brasileira, baseado na APG II. Nova Odessa, Instituto Plantarum.

Tongco, M.D.C. 2007. Purposive sampling as a tool for an informant selection. Ethnobotany Research \& Applications 5: 147-158.

Zanoni, M.M.; Ferreira, A.D.D.; Miguel, L. de A.; Floriani, D.; Canali, N.; Raynaut, C. 2000. Preservação da natureza e desenvolvimento rural: dilemas e estratégias dos agricultores familiares em Áreas de Proteção Ambiental. Desenvolvimento e Meio Ambiente 2: 39-55.

Versão eletrônica do artigo em www.scielo.br/abb e http://www.botanica.org.br/acta/ojs 